Article

\title{
Sustainable Sport Scheduling Approach Considering Team Equity for the Korean Professional Baseball League
}

\author{
Young Dae Ko ${ }^{1, * \mathbb{C}}$, Seung Hwan Jung ${ }^{2}$, Sung Hee Kim ${ }^{2}$ and Sung Wook Lee ${ }^{2}$ \\ 1 Department of Hotel and Tourism Management, College of Hospitality and Tourism, Sejong University, \\ Seoul 05006, Korea \\ 2 Data Analytics Group, Deloitte Consulting, Seoul 07326, Korea; seujung@deloitte.com (S.H.J.); \\ sunghekim2@deloitte.com (S.H.K.); sungwlee@deloitte.com (S.W.L.) \\ * Correspondence: youngdae.ko@sejong.ac.kr; Tel.: +82-2-6935-2490
}

Received: 30 October 2017; Accepted: 6 February 2018; Published: 7 February 2018

\begin{abstract}
Since the Korea Baseball League (KBL) had nine teams, an odd number, in the 2013 season, one team was unable to compete at certain times in the rotation while the other eight teams played games. Therefore, it was necessary to consider several elements to generate an annual match schedule in terms of team equity. However, the annual match schedule created by the conventional method could not fully reflect the elements regarding team equity, and there were a great many complaints from teams and fans. As a result, applying an optimization technique was decided upon to derive an efficient annual match schedule for the 2014 season. All the required conditions for scheduling are formulated as one or more equations and several parameter values concerning team equity are calculated with the related equations. Due to the complicated scheduling conditions, a sequential solution approach is applied by dividing the overall planning horizon in three parts. The derived annual match schedule was used for the 2014 season after some modifications, and the staff of the KBL was satisfied with the performance of the proposed scheduling methodology. Currently, this sustainable scheduling methodology is still in use to generate an efficient annual match schedule for the KBL.
\end{abstract}

Keywords: sport scheduling; sport management; operations research; mathematical model; optimization

\section{Introduction}

\subsection{Issues of an Annual Match Scheduling}

The KBL is managed by the Korean Baseball Organization (KBO), and an annual match schedule has been developed and announced on every November or December of the preceding year. However, there were several issues when the KBO introduced the annual match schedule for the 2013 season. Due to the NC Dinos joining the league as the ninth team, there were some changes in the features of the annual match schedule. Among them, one of the significant elements was the inevitable occurrence of the 'long rest' team. Due to the odd number of teams, one team was unable to compete, while the other eight teams played games on a certain day in the rotation. In the KBL, once the games are matched among eight teams, each team plays two or three consecutive days with same opponent team. Therefore, one team without an opponent would rest on those days. We called those rest days as 'long rest', and each team should have received six long rests during the planned annual match schedule.

In general, it is thought that a certain team which has to play a game with a team both before and after the long rest would be at a disadvantage. The team before the long rest can exert all its power 
without having to consider the next game. In addition, the team after the long rest can play a game with the players in rested condition because all the players of that team have had sufficient relaxation for an extra day. Therefore, when the annual match schedule is developed, the number of games with a team both before and after the long rest should be allocated as equally as possible.

Unfortunately, however, the first version of an annual match schedule for 2013 season did not satisfy the above conditions. As shown in Table 1, Lotte was scheduled to play a game with a team after the long rest about 12 times, while Samsung was scheduled for only one such game, and the average number of games with a team after the long rest is almost 6.6. Therefore, some teams strongly protested against the inequity elements of an annual match schedule for 2013 season. As a result, the $\mathrm{KBO}$ revised the annual match schedule for 2013 season considering the concept of team equity. It was an unprecedented occurrence in the history of the $\mathrm{KBO}$ because the right of development of an annual match schedule is regarded as their responsibility and area of expertise. Note that the " $i \rightarrow j$ " of Table 1 represents that " $i$ " is the number of games with a team before/after the long rest in initial version of an annual match schedule for 2013 season, while " $j$ " is the number of that in revised version.

Table 1. Inequity elements of the initial and revised annual match schedule for 2013 season.

\begin{tabular}{cccccccccc}
\hline Team Name & Samsung & SK & Doosan & Lotte & KIA & Nexen & LG & Hanwha & NC \\
\hline $\begin{array}{c}\text { The numbers of games with a } \\
\text { team before the long rest }\end{array}$ & $4 \rightarrow 4$ & $5 \rightarrow 5$ & $\underline{10} \rightarrow 8$ & $\underline{3} \rightarrow 6$ & $5 \rightarrow 7$ & $8 \rightarrow 5$ & $8 \rightarrow 6$ & $4 \rightarrow 7$ & $6 \rightarrow 5$ \\
\hline $\begin{array}{c}\text { The numbers of games with a } \\
\text { team after the long rest }\end{array}$ & $\underline{1} \rightarrow 6$ & $4 \rightarrow 5$ & $9 \rightarrow 5$ & $\underline{12} \rightarrow 7$ & $3 \rightarrow 4$ & $4 \rightarrow 6$ & $4 \rightarrow 6$ & $8 \rightarrow 6$ & $8 \rightarrow 8$ \\
\hline Total & $\underline{5} \rightarrow 10$ & $9 \rightarrow 10$ & $\underline{19} \rightarrow 13$ & $15 \rightarrow 13$ & $8 \rightarrow 11$ & $12 \rightarrow 11$ & $12 \rightarrow 12$ & $12 \rightarrow 13$ & $14 \rightarrow 13$ \\
\hline
\end{tabular}

In the wake of this event, the $\mathrm{KBO}$ tried to change the development procedure of the annual match schedule. Until that time, the scheduling had been generated by the scheduling manager of the $\mathrm{KBO}$ by hand via the trial and error method, taking almost one month each time. However, they subsequently adopted a scientific decision-making methodology, optimization based on mathematical modeling, for the development of an annual match schedule. Now, with the proposed optimization methodology described in this paper, an annual match schedule can be generated with various scheduling conditions within only three hours.

\subsection{Structure of an Annual Match Schedule}

In the KBL, an annual match schedule consists of a series of three tournaments, and each tournament is scheduled as a double round-robin. In addition, each round is repeated three times in the first and second tournaments, while it is repeated two times in the third tournament. That is, if teams $i$ and $j$ have a plan to play a game at certain round in the first and second tournaments, they should also play a game on the next day and the day after that-three consecutive days-while only playing the next day (and not the day after that)—two consecutive days—in the third tournament.

\section{Previous Studies}

There are several research articles about the scheduling issues in baseball leagues. Russell and Leung [1] maximized the number of schedule breaks in order to construct a new, balanced schedule that minimized travel costs for a baseball league. Yang et al. [2] suggested the scheduling problem in Major League Baseball (MLB) based on the concept of an evolution strategy. They developed an algorithm aiming to minimize travel costs, and every team had a balanced number of games at home. Recently, Hoshino and Kawarabayashi [3] presented two heuristics that minimized the sum distances traveled by all teams for the Nippon Professional Baseball (NPB). Compared to the 2010 NPB inter-league schedule, the proposed schedule reduced the total travel distance by $15.3 \%$. Jeong et al. [4] sought to maximize the fairness of the round-robin tournament schedule of the Korean Baseball League. The standard deviation of the travel distances of teams was defined as the energy function, 
and the Metropolis Monte-Carlo method combined with simulated annealing techniques was applied to find the ground-state configuration. Lin and Chen [5] suggested efficiency monitoring systems about match-fixing players for the Chinese Professional Baseball League. They adopted a weighted moving average to confirm whether there was an efficiency variation of players over the years.

There are some studies on the scheduling in sports, as surveyed in Kendall et al. [6]. They provided an annotated bibliography for sports scheduling articles, including over 160 papers, with the earliest published in 1968, and categorized the scheduling problems according to problem definitions, methodologies, and applications. In addition, they analyzed papers by year and journal. The traveling tournament problem (TTP) is widely known as a variant of sport league tournament. Nemhauser and Trick [7] proposed TTP using a combination of integer programming and constraint programming to generate feasible schedules for the American League of Major League Baseball (MLB) in the United States. Benoist et al. [8] suggested a set of hybrid algorithms combining Lagrange Relaxation techniques with constraint programming. Anagnostopoulos et al. [9] proposed a heuristic algorithm based on the simulated annealing approach for Major League Baseball (MLB). Their proposed simulated annealing algorithm used a large neighborhood with complex moves, and included advanced techniques such as strategic oscillation. Ribeiro and Urrutia [10] suggested a new heuristic algorithm to minimize the total distance traveled by the teams; the suggested algorithm was based on a combination of the GRASP (greedy randomized adaptive search procedure) and ILS (iterated local search) meta-heuristics, which provide high-quality solutions. Russel and Urban [11] considered the scheduling problem of sports competitions over several venues that are not associated with any of the competitors and developed a two-phase approach. First, the method identifies a solution that designates the participants and schedules of each of the competitions and then assigns each competitor as "home" or "away." Recently, Briskorn and Drexl [12] proposed a branch-and-price approach to generate optimal solutions, while Wright [13] presented a case study for a real-world sports scheduling problem. In addition, Jakee et al. [14] introduced asymmetries in scheduling slots and game-day revenues by considering the Australian Football League.

In this study, we generate a sustainable annual match schedule for the professional baseball league of Korea considering team equity when the number of teams is odd. We perform the scheduling through the optimization technique based on mathematical modeling, which is one of the well-known quantitative analysis methods. Such approaches have been used widely in sports management fields, such as the decision of ticket pricing, viability evaluation of professional sports teams, and the development of revenue-sharing policies between players [15-18]. By reflecting the needs of the fans and the teams, this sustainable sport scheduling approach can maintain its reputation for fairness, as well as the popularity of the KBL $[19,20]$.

\section{Scheduling Methodology}

Adopting an optimization technique was decided upon based on mathematical modeling to derive an efficient annual schedule for the KBL. The overall procedure is designed in Figure 1.

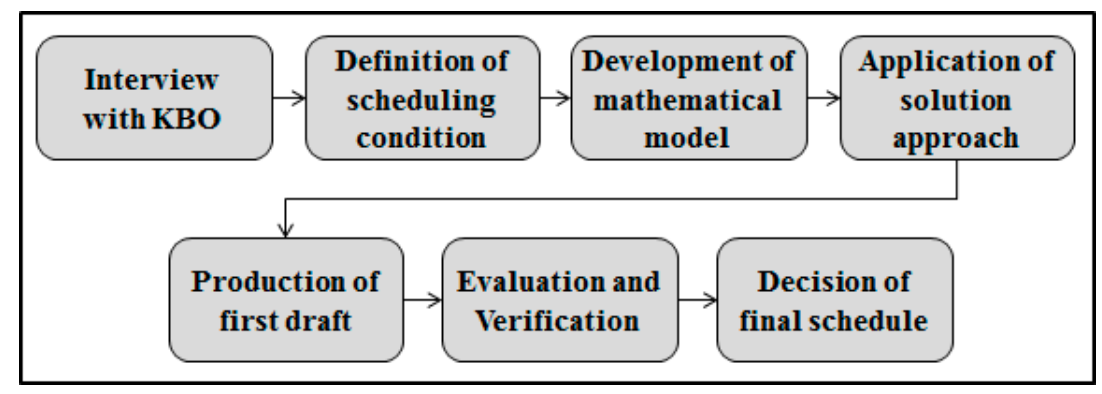

Figure 1. Overall procedure for development of an annual match schedule. 


\subsection{Scheduling Conditions}

Through several interviews with the KBO, we ascertained the required scheduling conditions as follows:

1. Nine teams are considered in the 2014 season (see Table 2).

2. The total number of games in the 2014 season is set as 576 games. Therefore, each team should have 128 games, meaning that there are $16(128 / 8)$ games for each pair of teams.

3. The overall schedule for 2014 season consists of a series of three tournaments, where each tournament has 18 rounds. Each round continues for three days and two days consecutively in both the first and second tournaments and the third tournament, respectively.

4. In each tournament, any team should play on two rounds against every other team-one game at home and the other game away.

5. Each week, there are no games on Monday. In the first and second tournaments, two rounds are operated from Tuesday to Sunday: Tuesday to Thursday and Friday to Sunday. On the other hand, in the third tournament, three rounds are operated from Tuesday to Sunday: Tuesday to Wednesday, Thursday to Friday, and Saturday to Sunday.

6. In each round, one team should have the long rest because of the odd number of teams. That is, eight teams should play, while one team should rest on a certain game day.

7. Each team should have the long rest twice in each tournament.

8. No team is allowed to play more than six consecutive home/away games.

9. LG and Doosan share the Jamsil Stadium as home. Therefore, they are not allowed to play more than six consecutive games at the Jamsil Stadium. This assumption is made to prevent both LG and Doosan having more than six consecutive games by home-home-away, home-away-home, away-home-home, or vice versa configurations.

10. Every team should play an away game at all stadiums on a weekend or Friday at least once during a season.

11. It is desirable to assign a certain team to play with a specific team at the designated date to increase the popularity of the KBL (ex. Opening Day, Children's Day).

12. There is always a game at the Jamsil Stadium on a weekend because of the popularity.

13. The number of monthly and whole scheduled home games for each team should be organized as evenly as possible to control home field advantage [21,22].

14. In the case of LG, Doosan, Nexen, and SK, the number of scheduled home games on a weekend with either Lotte or KIA should be organized as evenly as possible.

15. The number of games that are played with a team before and after the long rest should be assigned as evenly as possible.

16. The order of the long rest teams should be scheduled as uniformly as possible.

Table 2. Team names and their home ground city in 2014 season.

\begin{tabular}{cccc}
\hline$\#$ & Team Name & Stadium & Region \\
\hline 1 & NC Dinos & Changwon & Changwon \\
2 & Samsung Lions & Deagu & Deagu \\
3 & KIA Tigers & Gwangju & Gwangju \\
4 & Lotte Giants & Sajik & Busan \\
5 & Hanwha Eagles & Daejeon & Daejeon \\
6 & SK Wyverns & Munhak & Incheon \\
7 & Nexen Heroes & Mokdong & Seoul \\
8 & LG Twins & Jamsil & Seoul \\
9 & Doosan Bears & Jamsil & Seoul \\
\hline
\end{tabular}

\subsection{Mathematical Model Development}

Considering the required scheduling conditions from the $\mathrm{KBO}$, we developed a mathematical model with the form of integer programming. The decision variables, which are about whether the 
certain team has a game on a designated day or not and whether the certain team pair have a game on a designated day or not, are defined as binary $0-1$ variables. Each condition mentioned in the Scheduling Conditions section above is described by one or more mathematical formulations using decision variables and several parameters to consider specific meanings.

\section{Constraints}

Constraints (1)-(9) are used to represent the general rules for the scheduling. Constraints (1)-(4) mean that each team plays 16 rounds within a tournament, while constraints (5)-(7) show that eight teams play the game in each round. In addition, constraints (8) and (9) are about the double round robin rule. Constraints (10)-(14) mean that each team is not allowed to play more than six home/away games consecutively. Moreover, constraints (15)-(20) are used to prevent playing nine home/away games in a row at Jamsil Stadium because both LG and Doosan use the same stadium. Thus, constraints (15)-(20) have the same purpose as constraints (10)-(14). Constraints (21)-(25) explain the specific round set for the opening game. Accordingly, several special round sets should be assigned on a designated date. Constraints (26)-(28) are related with the round operation of Jamsil Stadium on weekends. Jamsil Stadium should have a round every weekend, while it does not need to operate a round on every weekday. Constraint (29) means that every team should have an away game on each weekend at least once. The remaining constraints, (30)-(40), are about the equations to represent team equity. According to the derived match schedules, they are set to have certain lower or upper bounds to adjust the performances of the match schedule. Constraint (30) means the number of home games on a weekend for each team, while constraints (31)-(36) depict the number of home games at each month for each team. In addition, constraints (37) and (38) and constraints (39) and (40) describe the number of games before and after the long rest, respectively. Finally, constraints (41) and (42) mean the binary decision variables while constraint (43) is a nonnegative constraint.

$$
\begin{array}{cc}
\sum_{k=1}^{9} x_{i, r, k}=8, & \forall i, \forall r \\
\sum_{k=10}^{18} x_{i, r, k}=8, & \forall i, \forall r \\
x_{i, r, k}+x_{i^{\prime}, r, k} \geq 2\left(y_{i, i^{\prime}, r, k}+y_{i^{\prime}, i, r, k}\right), & \forall i, i^{\prime} \in I\left(i^{\prime} \neq i\right), \forall r, \forall k \\
y_{i, i, r, k}=0, & \forall i, \forall r, \forall k \\
\sum_{i=1}^{I} x_{i, r, k}=8, & \forall r, \forall k \\
\sum_{i=1}^{I} \sum_{i^{\prime}=1}^{I} y_{i, i^{\prime}, r, k}=4, & \forall r, \forall k \\
\sum_{i^{\prime}=1}^{I} y_{i, i^{\prime}, r, k}+\sum_{i^{\prime}=1}^{I} y_{i^{\prime}, i, r, k}=x_{i, r, k}, & \forall i, \forall r, \forall k \\
\sum_{k=1}^{K} y_{i, i^{\prime}, r, k}=1, & \forall i, i^{\prime} \in I\left(i^{\prime} \neq i\right), \forall r \\
\sum_{k=1}^{K} y_{i^{\prime}, i, r, k}=1, & \forall i, i^{\prime} \in I\left(i^{\prime} \neq i\right), \forall r \\
\sum_{i^{\prime}=1}^{I} y_{i, i^{\prime}, r, k}+\sum_{i^{\prime}=1}^{I} y_{i, i^{\prime}, r, k+1}+\sum_{i^{\prime}=1}^{I} y_{i, i^{\prime}, r, k+2} \leq 2, & \forall i, \forall r, k=1, \ldots, K-2
\end{array}
$$




$$
\begin{aligned}
& \sum_{i^{\prime}=1}^{I} y_{i^{\prime}, i, r, k}+\sum_{i^{\prime}=1}^{I} y_{i^{\prime}, i, r, k+1}+\sum_{i^{\prime}=1}^{I} y_{i^{\prime}, i, r, k+2} \leq 2, \quad \forall i, \forall r, k=1, \ldots, K-2 \\
& x_{i, r, k}+x_{i, r, k+1} \geq 1, \quad \forall i, \forall r, k=1, \ldots, K-1 \\
& y_{i, i^{\prime}, r, k}+y_{i^{\prime}, i, r, k}+y_{i, i^{\prime}, r, k+1}+y_{i, i^{\prime}, r, k+2}+y_{i^{\prime}, i, r, k+2} \leq 1 \text {, } \\
& \forall i, i^{\prime} \in I\left(i^{\prime} \neq i\right), k=1, \ldots, K-2 \\
& \sum_{i^{\prime}=1}^{I} y_{i^{\prime}, 8, r, k}+\sum_{i^{\prime}=1}^{I} y_{i^{\prime}, 9, r, k} \leq 1, \quad \forall r, \forall k \\
& \sum_{i^{\prime}=1}^{I} y_{i^{\prime}, 8, r, k}+\sum_{i^{\prime}=1}^{I} y_{i^{\prime}, 8, r, k+1}+y_{8,9, r, k+2} \leq 2, \quad \forall r, k=1, \ldots, K-2 \\
& \sum_{i^{\prime}=1}^{I} y_{i^{\prime}, 8, r, k}+y_{8,9, r, k+1}+\sum_{i^{\prime}=1}^{I} y_{i^{\prime}, 8, r, k+2} \leq 2, \quad \forall r, k=1, \ldots, K-2 \\
& y_{8,9, r, k}+\sum_{i^{\prime}=1}^{I} y_{i^{\prime}, 8, r, k+1}+\sum_{i^{\prime}=1}^{I} y_{i^{\prime}, 8, r, k+2} \leq 2, \quad \forall r, k=1, \ldots, K-2 \\
& \sum_{i^{\prime}=1}^{I} y_{i^{\prime}, 9, r, k}+\sum_{i^{\prime}=1}^{I} y_{i^{\prime}, 9, r, k+1}+y_{9,8, r, k+2} \leq 2, \quad \forall r, k=1, \ldots, K-2 \\
& \sum_{i^{\prime}=1}^{I} y_{i^{\prime}, 9, r, k}+y_{9,8, r, k+1}+\sum_{i^{\prime}=1}^{I} y_{i^{\prime}, 9, r, k+2} \leq 2, \quad \forall r, k=1, \ldots, K-2 \\
& y_{9,8, r, k}+\sum_{i^{\prime}=1}^{I} y_{i^{\prime}, 9, r, k+1}+\sum_{i^{\prime}=1}^{I} y_{i^{\prime}, 9, r, k+2} \leq 2, \quad \forall r, k=1, \ldots, K-2 \\
& x_{i, 1,1}=1, \quad i=2,3,4,5,6,7,8,9 \\
& y_{3,2,1,1}=1 \\
& y_{7,6,1,1}=1 \\
& y_{8,9,1,1}=1 \\
& y_{5,4,1,1}=1 \\
& \sum_{i^{\prime}=1}^{I} y_{i^{\prime}, 8,1, k}+\sum_{i^{\prime}=1}^{I} y_{i^{\prime}, 9,1,} \quad k=1, k=1,3,5,6,9,11,13,15,17 \\
& \sum_{i^{\prime}=1}^{I} y_{i^{\prime}, 8,2, k}+\sum_{i^{\prime}=1}^{I} y_{i^{\prime}, 9,2, k}=1, \quad k=1,3,5,6,9,11,13,16,18 \\
& \sum_{i^{\prime}=1}^{I} y_{i^{\prime}, 8,3, k}+\sum_{i^{\prime}=1}^{I} y_{i^{\prime}, 9,3, k}=1 \quad, k=3,6,9,12,15,18 \\
& \sum_{k \in\{1,3,5,7,9,11,12,13,15,17\}} y_{i, i^{\prime}, 1, k}+\sum_{k \in\{1,3,5,7,9,11,13,16,18\}} y_{i, i^{\prime}, 2, k}+\sum_{k \in\{3,5,6,9,12,15,16,18\}} y_{i, i^{\prime}, 3, k} \geq 1, \\
& \forall i, i^{\prime} \in I\left(i^{\prime} \neq i\right) \\
& \begin{array}{l}
\sum_{k \in\{1,3,5,7,9,11,12,13,15,17\}} \sum_{i^{\prime}=1}^{I} y_{i^{\prime}, i, 1, k}+\sum_{k \in\{1,3,5,7,9,11,13,16,18\}} \sum_{i^{\prime}=1}^{I} y_{i^{\prime}, i, 2, k} \\
+\sum_{k \in\{3,5,6,9,12,15,16,18\}} \sum_{i^{\prime}=1}^{I} y_{i^{\prime}, i, 3, k}=N_{\text {holiday }, i},
\end{array} \\
& \sum_{k=1}^{9} \sum_{i^{\prime}=1}^{I} y_{i^{\prime}, i, 1, k}=N_{\text {home }, i, 4} \\
& \forall i
\end{aligned}
$$




$$
\begin{aligned}
& \sum_{k=10}^{18} \sum_{i^{\prime}=1}^{I} y_{i^{\prime}, i, 1, k}=N_{\text {home }, i, 5} \quad \forall i \\
& \sum_{k=1}^{9} \sum_{i^{\prime}=1}^{I} y_{i^{\prime}, i, 2, k}=N_{\text {home }, i, 6}, \quad \forall i \\
& \sum_{k=10}^{18} \sum_{i^{\prime}=1}^{I} y_{i^{\prime}, i, 2, k}=N_{\text {home }, i, 7} \quad \forall i \\
& \sum_{k=1}^{12} \sum_{i^{\prime}=1}^{I} y_{i^{\prime}, i, 3, k}=N_{\text {home }, i, 8} \quad \forall i \\
& \sum_{k=13}^{18} \sum_{i^{\prime}=1}^{I} y_{i^{\prime}, i, 3, k}=N_{h o m e, i, 9}, \forall i \\
& y_{i, i^{\prime}, r, k}+y_{i^{\prime}, i, r, k}-x_{i^{\prime}, r, k+1}=2 z_{i, r, k}^{1}-z_{i, r, k}^{2} \quad \forall i, i^{\prime}=I-\{i\}, \quad \forall r, k=1, \ldots, K-1 \\
& \sum_{r=1}^{R} \sum_{k=1}^{K-1} z_{i, r, k}^{1}=N_{b e f o r e r e s t, i} \quad \forall i \\
& y_{i, i^{\prime}, r, k}+y_{i^{\prime}, i, r, k}-x_{i^{\prime}, r, k-1}=2 z_{i, r, k}^{3}-z_{i, r, k^{\prime}}^{4} \quad \forall i, i^{\prime}=I-\{i\}, \forall r, k=2, \ldots, K \\
& \sum_{r=1}^{R} \sum_{k=2}^{K} z_{i, r, k}^{3}=N_{\text {afterrest }, i} \quad \forall i \\
& x_{i, r, k}, y_{i, i^{\prime}, r, k} \in\{0,1\}, \quad \forall i, i^{\prime}, r, k \\
& z_{i, r, k}^{1}, z_{i, r, k}^{2}, z_{i, r, k}^{3} z_{i, r, k}^{4} \in\{0,1\}, \quad \forall i, r, k \\
& N_{\text {holiday }, i}, N_{\text {home }, i, t}, N_{\text {beforerest }, i}, N_{\text {afterrest }, i} \text { is nonnegative integer } \quad \forall i, t
\end{aligned}
$$

In this study, the required scheduling conditions given from the $\mathrm{KBO}$ are extremely tight. In addition, there are several unconsidered scheduling conditions that are hard to express in exact words, even though they have some concepts and images by themselves. Therefore, we do not present their objective function in the proposed mathematical model. That is, if some feasible solutions are generated during the solution procedure, those solutions can be regarded as possible match schedules for the KBL. After that, the most suitable match schedule will be selected as the most preferred schedule for next season by the $\mathrm{KBO}$, considering many undefined elements, such as the number of expected spectators, weather, special events, and so on.

\section{Solution Approach}

\subsection{Approach Description}

To find appropriate candidates of the match schedule through the proposed mathematical model, CPLEX version 12.4 is adopted. Since the number of decision variables, $x_{i, r, k}$ and $y_{i, i, r, k}$ is $9 \times 3 \times 18=486$ and $9 \times 9 \times 3 \times 18=4374$, respectively, it is difficult to find an optimal or near-optimal solution through heuristic approaches. Even though meta-heuristics, such as genetic algorithm, Tabu search, and simulated annealing are employed, it is a challenge to obtain a feasible solution reflecting all required schedule conditions based on their penalty-function-based improvement algorithm. Therefore, we initially developed the mathematical model as a form of integer programming to adopt the CPLEX in this study.

However, unfortunately, we could not obtain a feasible solution within $86,400 \mathrm{~s}$ (one day). As a result, we attempted alternative approaches to obtain an appropriate match schedule for the KBL. 


\subsection{Modified Approach}

To cope with this obstacle, we inevitably decide to divide the proposed mathematical model into each tournament level. The overall procedures of the modified approach are as follows:

STEP 1-1: Apply the proposed mathematical model only to the first tournament $(r=1)$.

STEP 1-2: Derive the match schedule of the first tournament by using the CPLEX, and save the related values of decision variables.

Apply the proposed mathematical model to the second tournament $(r=2)$. In this step, we have

STEP 2-1: $\quad$ to consider the result of the decision variables from STEP 1-2 and boundary conditions between first and second tournaments.

STEP 2-2: Derive the match schedule of the second tournament by using the CPLEX and save the related values of decision variables.

Apply the proposed mathematical model to the third tournament $(r=3)$. In this step, we also

STEP 3-1: $\quad$ have to consider the result of the decision variables from both STEP 1-2 and STEP 2-2 and boundary conditions between second and third tournaments.

STEP 3-2: Derive the match schedule of the third tournament by using the CPLEX, and save the related values of decision variables.

STEP 4: $\quad$ Generate an annual match schedule for the KBL based on the values of decision variables.

As boundary conditions, several constraints concerning team equity, such as the number of games played before and after the long rest, the number of home games in each month during the season, and the number of home games on a weekend or holiday are set to have upper or lower bounds at the end of each tournament. As a result, the computation time for small problems for the first and second tournaments is less than $10 \mathrm{~min}$, while that for the small problem for the third tournament is less than $2 \mathrm{~h}$. The average computation time is no more than three hours within our experiment. Therefore, we could generate many annual match schedules for the KBL by changing the parameter values of several constraints derived from our discussion with the KBO staff. After several repeated proposals, the staff from the $\mathrm{KBO}$ was able to determine the most preferred candidate among the proposed annual match schedules from our approach.

\section{Numerical Experiments}

To validate an annual match schedule derived through our methodology, we compared several aspects concerning team equity in the official schedules for the 2013 and the 2014 seasons with a schedule generated by our approach for the 2014 season.

Table 3 shows the number of games with a team before and after the long rest for each team. The distribution of the number of games with a team before the long rest in the 2013 season ranges from four to eight, while it ranges from five to seven in our version. In the case of the actual 2014 season, which is modified by the $\mathrm{KBO}$ with our version, the distribution ranges from three to ten. In addition, the distribution of the number of games with a team after the long rest both in the 2013 season and, in our version, ranges from four to eight games, while the range is from three to nine for the actual 2014 season. In this case, we notice that the gap between large and small values is more often shorter in our version. In addition, we can see that the gap is quite significant in the 2014 season. This is because the KBO does not consider each of the number of games with a team before and after the long rest. They only have an interest in the sum of both the number of games with a team before and after the long rest. The distribution of the sum of two cases in the 2013 season, our version, and the 2014 season ranges from 10 to 13 games, from 11 to 14 games, and from 10 to 14 games, respectively. Even though the gap in the 2014 season is greater than the others, its standard deviation is smaller than that of the 2013 season.

Table 4 addresses the number of home games in each month for each team. The standard variations of the number of home games in each month for each team are generated quite equitably, within the range of 1.5 to 2.0. Therefore, we can check that the proposed annual match schedule has a similar performance in comparison to the 2013 version. 
Table 3. Distribution of the numbers of games with a team before/after the long rest.

\begin{tabular}{ccccccccccc}
\hline \multicolumn{1}{c}{ Team Name } & Samsung & SK & Doosan & Lotte & KIA & Nexen & LG & Hanwha & NC \\
\hline The numbers of & 2013 & 4 & 5 & 8 & 6 & 7 & 5 & 6 & 7 & 5 \\
games with a team & proposed & 5 & 5 & 6 & 6 & 7 & 6 & 5 & 6 & 7 \\
before the long rest & 2014 & 6 & 10 & 4 & 5 & 3 & 8 & 6 & 6 & 5 \\
\hline The numbers of & 2013 & 6 & 5 & 5 & 7 & 4 & 6 & 6 & 6 & 8 \\
games with a team & proposed & 7 & 6 & 6 & 5 & 4 & 5 & 8 & 5 & 7 \\
after the long rest & 2014 & 4 & 3 & 8 & 7 & 9 & 3 & 5 & 8 & 6 \\
\hline \multirow{2}{*}{ Total (standard } & $2013(1.30)$ & 10 & 10 & 13 & 13 & 11 & 11 & 12 & 13 & 13 \\
deviation) & Proposed (1.09) & 12 & 11 & 12 & 11 & 11 & 11 & 13 & 11 & 14 \\
& $2014(1.20)$ & 10 & 13 & 12 & 12 & 12 & 11 & 11 & 14 & 11 \\
\hline
\end{tabular}

Table 4. Distributions of the number of home game at each month for each team.

\begin{tabular}{cccccccccccc}
\hline Version & Month & Samsung & SK & Doosan & Lotte & KIA & Nexen & LG & Hanwha & NC & S.D. \\
\hline \multirow{6}{*}{2013} & March & 2 & 2 & 0 & 2 & 2 & 0 & 0 & 0 & 0 & 1.054 \\
& April & 13 & 9 & 10 & 9 & 9 & 12 & 12 & 13 & 13 & 1.833 \\
version & May & 9 & 12 & 15 & 12 & 13 & 12 & 12 & 12 & 11 & 1.581 \\
& June & 11 & 9 & 11 & 12 & 11 & 12 & 12 & 14 & 12 & 1.333 \\
& July & 12 & 10 & 11 & 10 & 7 & 11 & 9 & 9 & 9 & 1.481 \\
& August & 12 & 14 & 13 & 12 & 15 & 11 & 9 & 9 & 13 & 2.062 \\
& September & 5 & 8 & 4 & 7 & 7 & 6 & 10 & 7 & 6 & 1.732 \\
\hline \multirow{6}{*}{ Proposed } & March & 3 & 3 & 3 & 3 & 0 & 0 & 0 & 0 & 0 & 1.581 \\
version & April & 12 & 12 & 12 & 9 & 12 & 15 & 12 & 12 & 12 & 1.500 \\
& May & 9 & 12 & 12 & 12 & 15 & 12 & 12 & 12 & 12 & 1.500 \\
& June & 12 & 6 & 9 & 12 & 12 & 9 & 12 & 12 & 12 & 2.179 \\
& July & 12 & 15 & 12 & 9 & 9 & 12 & 9 & 9 & 9 & 2.179 \\
& August & 10 & 10 & 10 & 15 & 12 & 10 & 13 & 15 & 13 & 2.121 \\
& September & 6 & 6 & 6 & 4 & 4 & 6 & 6 & 4 & 6 & 1.000 \\
\hline \multirow{6}{*}{2014} & March & 3 & 3 & 3 & 3 & 0 & 0 & 0 & 0 & 0 & 1.581 \\
version & April & 9 & 9 & 12 & 12 & 12 & 12 & 12 & 15 & 15 & 2.121 \\
& May & 12 & 12 & 12 & 9 & 15 & 15 & 12 & 12 & 9 & 2.121 \\
& June & 12 & 12 & 12 & 12 & 9 & 9 & 9 & 9 & 12 & 1.581 \\
& July & 12 & 9 & 9 & 12 & 9 & 12 & 12 & 9 & 12 & 1.581 \\
& August & 12 & 11 & 12 & 12 & 15 & 10 & 13 & 13 & 10 & 1.581 \\
& September & 4 & 8 & 4 & 4 & 4 & 6 & 6 & 6 & 6 & 1.414 \\
\hline
\end{tabular}

Table 5 represents the number of home games on weekends or holidays for each team. The distribution of the number of home games on weekends or holidays in the 2013 season ranges from 11 to 13, while our version varies from 12 to 14 . In the case of 2014 season, which is modified by the $\mathrm{KBO}$ from our version, the figure ranges from 11 games to 14 games. The standard deviations of 2013 version, proposed version, and the 2014 version are calculated as $0.71,0.88$, and 1.13 , respectively. In addition, in this element, the proposed annual match schedule shows almost the same performance as the 2013 version.

Note that we do not compare the initial schedule of 2013 season due to its very low performance (see the Table 1). In addition, an annual match schedule for the 2014 season was designed and modified by our proposed annual match schedule, reflecting several elements such as popularity, the expected number of spectators, and the specific designated date.

Table 5. Distributions of the number of home game in weekend or in holiday.

\begin{tabular}{ccccccccccc}
\hline Version & Samsung & SK & Doosan & Lotte & KIA & Nexen & LG & Hanwha & NC & S.D. \\
\hline 2013 & 11 & 12 & 13 & 12 & 12 & 12 & 13 & 11 & 12 & 0.71 \\
Proposed & 12 & 12 & 14 & 12 & 12 & 12 & 14 & 12 & 12 & 0.88 \\
2014 & 11 & 13 & 14 & 14 & 11 & 12 & 13 & 12 & 12 & 1.13 \\
\hline
\end{tabular}




\section{Conclusions}

Until we proposed and derived an efficient schedule methodology for the KBL through the optimization based on mathematical modeling, an annual match schedule was made by the staff of the $\mathrm{KBO}$ by hand. This approach took almost one month to generate an annual match schedule and several required schedule conditions were inevitably neglected. If they wanted to adjust several elements, it was impossible to spend an extra month to recalibrate. Thus, there was the possibility of several unfair elements for a certain team, and that issue became a significant issue in the 2013 season. However, after adopting our schedule methodology, the KBO can obtain many candidates of annual match schedules within a reasonable time, and they can select the most appropriate one among them. In addition, if they want to reflect other circumstances or to adjust some parameter values for team equity, a new set of candidates can be produced with a few modifications of the mathematical model. Moreover, when the number of teams in the league is changed in the future, this can be also reflected in the mathematical model, and an appropriate annual match schedule for the $\mathrm{KBO}$ under the changed environment can be delivered.

The strength of this paper is the explanation of the sustainable scheduling methodology as actually applied to the Korean professional baseball league, which via this methodology, can generate an efficient annual match schedule reflecting various needs from teams and fans. With those features, the KBL can maintain its reputation for fairness and popularity. Although several papers deal with sports scheduling, they were merely academic studies, with few examples having been applied. However, this manuscript is a result applied to the actual Korean professional baseball league.

Furthermore, the fans and the managers of each team can rest assured because the annual match schedule is planned with the utmost equity. Therefore, this study also gives some positive effects to increase the popularity of the KBL. As further work, if sufficient data related to the number of spectators of each game is gathered, it would be possible to design an optimal scheduling methodology for the KBL with the objective of maximizing the total number of spectators for a given season.

Author Contributions: Young Dae Ko defined proposed problem and developed the mathematical models and prepared this manuscript. Seung Hwan Jung developed the solution procedure, while Sung Hee Kim and Sung Wook Lee supervised the work.

Conflicts of Interest: The authors declare no conflict of interest.

\section{Abbreviation}

$i \quad$ Index for team while there are $I$ number of teams

$r \quad$ Index for tournament while there are $R$ number of tournaments

$k \quad$ Index for round while there are $K$ number of rounds

$x_{i, k} \quad$ Binary decision variable that equals 1 if team $i$ has a game at round $k$ of tournament $r$; otherwise,

$x_{i, r, k} \quad$ it equals 0

$y_{i, i^{\prime}, r, k} \quad$ Binary decision variable that equals 1 if away team $i$ has a game with home team $i^{\prime}$ at round $k$ of

tournament $r$; otherwise, it equals 0

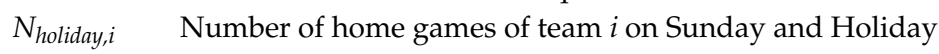

$N_{\text {home }, i, t} \quad$ Number of home games of team $i$ at each month $t$

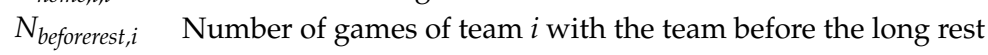

$N_{\text {afterrest, } i} \quad$ Number of games of team $i$ with the team after the long rest

$z_{i, r, k}^{1}, z^{2}{ }_{i, r, k}$ Binary decision variable for counting the number of games with the team before the long rest

$z_{i, r, k}^{3}, z_{i, r, k}^{4}$ Binary decision variable for counting the number of games with the team after the long rest

\section{References}

1. Russel, R.A.; Leung, J.M.Y. Devising a cost effective schedule for a baseball league. Oper. Res. 1994, 42, 614-625. [CrossRef]

2. Yang, J.T.; Huang, H.D.; Horng, J.T. Devising a cost effective baseball scheduling by evolutionary algorithm. In Proceedings of the 2002 Congress on Evolutionary Computation, Honolulu, HI, USA, 12-17 May 2002; pp. 1660-1665. 
3. Hoshino, R.; Kawarabayashi, K. The distance-optimal inter-league schedule for Japanese Pro Baseball. In Proceedings of the ICAPS 2011 Workshop on Constraint Satisfaction Techniques for Planning and Scheduling Problems, Freiburg, Germany, 11-16 June 2011; pp. 71-78.

4. Jeong, H.M.; Kim, S.W.; Choi, W.; Kim, A.J.; Eun, J.; Kim, B.J. Traveling baseball players problem in Korea. J. Korean Phys. Soc. 2012, 61, 484-492. [CrossRef]

5. Lin, W.B.; Chen, M.Y. A study of efficiency monitoring systems for match-fixing players in the Chinese Professional Baseball League. Eur. Sport Manag. Q. 2015, 15, 301-322. [CrossRef]

6. Kendall, G.; Knust, S.; Ribeiro, C.C.; Urritia, S. Scheduling in sports: An annotated bibliography. Comput. Oper. Res. 2010, 37, 1-19. [CrossRef]

7. Nemhauser, G.L.; Trick, M.A. Scheduling a Major College Basketball Conference. Oper. Res. 1998, 46, 1-8. [CrossRef]

8. Benoist, T.; Laburthe, F.; Rottembourg, B. Lagrange Relaxation and Constraint Programming Collaborative schemes for Traveling Tournament Problems. In Proceedings of the CPAIOR2001, Ashford, UK, 8-10 April 2001; pp. 15-26.

9. Anagnostopoulos, A.; Michel, L.; Hentenryck, P.V.; Vergados, Y. A simulated annealing approach to the traveling tournament problem. J. Sched. 2006, 9, 177-193. [CrossRef]

10. Ribeiro, C.C.; Urrutia, S. Heuristics for the mirrored traveling tournament problem. Eur. J. Oper. Res. 2007, 179, 775-787. [CrossRef]

11. Russel, R.A.; Urban, T.L. A constraint programming approach to the multiple-venue, sport-scheduling problem. Comput. Oper. Res. 2006, 33, 1895-1906. [CrossRef]

12. Briskorn, D.; Drexl, A. A branch-and-price algorithm for scheduling sport leagues. J. Oper. Res. Soc. 2009, 60, 84-93. [CrossRef]

13. Wright, M.B. Case study: Problem formulation and solution for a real-world sports scheduling problem. J. Oper. Res Soc. 2007, 58, 439-445. [CrossRef]

14. Jakee, K.; Kenneally, M.; Mitchell, H. Asymmetries in scheduling slots and game-day revenues: An example from the Australian Football League. Sport Manag. Rev. 2010, 13, 50-64. [CrossRef]

15. Rascher, D.A.; McEvoy, C.D.; Nagel, M.S.; Brown, M.T. Variable Ticket Pricing in Major League Baseball. J. Sport Manag. 2007, 21, 407-437. [CrossRef]

16. Wenz, M.G. A Proposal for Incentive-Compatible Revenue Sharing in Major League Baseball. J. Sport Manag. 2012, 26, 479-489. [CrossRef]

17. Yokum, J.T.; Gonzalez, J.J.; Badgett, T. Forecasting the Long-Term Viability of an Enterprise: The Case of a Minor League Baseball Franchise. J. Sport Manag. 2006, 20, 249-259. [CrossRef]

18. Shapiro, S.L.; Drayer, J. An examination of dynamic ticket pricing and secondary market price determinants in Major League Baseball. Sport Manag. Rev. 2014, 17, 145-159. [CrossRef]

19. Apanavičienè, R.; Daugèlienè, A.; Baltramonaitis, T.; Maliene, V. Sustainability aspects of real estate development: Lithuanian case study of sports and entertainment arenas. Sustainability 2015, 7, 6497-6522. [CrossRef]

20. Hu, K.H.; Chen, F.H.; Tzeng, G.H. Evaluating the improvement of sustainability of sports industry policy based on MADM. Sustainability 2016, 8, 606. [CrossRef]

21. Bray, S.R.; Obara, J.; Kwan, M. Batting last as a home advantage factor in men's NCAA tournament, baseball. J. Sport Sci. 2005, 23, 681-686. [CrossRef] [PubMed]

22. Pollard, R.; Pollard, G. Long-term trends in home advantage in professional team sports in North America and England (1876-2003). J. Sport Sci. 2005, 23, 337-350. [CrossRef] [PubMed]

(C) 2018 by the authors. Licensee MDPI, Basel, Switzerland. This article is an open access article distributed under the terms and conditions of the Creative Commons Attribution (CC BY) license (http://creativecommons.org/licenses/by/4.0/). 